\title{
A FAMILY OF ADENOSINE DEAMINASE DEFICIENCY WITH SEVERE COMBINED IMMUNODEFICIENCY
}

\author{
Shigeru TsuchIYA, Kuniaki Narisawa, Tasuke KonNo, and Keiya TADA \\ Department of Pediatrics, Tohoku University School of Medicine, Sendai, Japan
}

\begin{abstract}
Summary Adenosine deaminase (ADA) activities in erythrocytes from 10 relatives including parents of a patient with ADA deficiency and severe combined immunodeficiency (SCID) were reported. His parents, maternal uncle and grandmother showed ADA activity in their erythrocytes below the half level of the mean value of controls. These results suggested the autosomal recessive inheritance pattern of ADA deficiency, confirming other reports.
\end{abstract}

\section{INTRODUCTION}

The adenosine deaminase (ADA) deficiency associated with severe combined immunodeficiency (SCID) is a disease inherited in an autosomal recessive form (Giblett et al., 1975). All parents of the ADA deficients reported had ADA levels of erythrocytes significantly lower than controls and were assumed to be heterozygotes. The affected patients are homozygous for allele and have a "silent" gene (ADAo) (Chen et al., 1974).

Recently, we had a patient with ADA deficiency and SCID, the first case in Japan. Estimation of ADA activities of erythrocytes from 10 relatives of the patients revealed an autosomal recessive inheritance of the disease.

\section{CASE REPORT}

The patient was the product of a gravida 2, para 2 mother. The parents were nonconsanguinious. Two sisters were died of pneumonia at a year of age. One of them had hypogammaglobulinemia and hypoplasia of thymus and lymphoid organs shown by autopsy. The patient was admitted to Yamagata University Hospital with severe pulmonary candidasis at the age of 15 months, and suspected to have ADA deficiency disease. He was referred to our ward one month later for further examination and treatment including bone marrow transplantation. Marked lymphocytopenia, agammaglobulinemia, negative skin tests against candida, SK/SD and DNCB, and markedly decreased lymphocyte proliferative responses to phytohemagglutinin, pokeweed mitogen and concanavalin A were noticed (Yokoyama 
Table 1. Clinical and immunological data of the patient with ADA deficiency.

\begin{tabular}{|c|c|c|c|}
\hline Peripheral blood & & \multicolumn{2}{|c|}{ Lymphocyte surface markers } \\
\hline WBC & $5,000 / \mathrm{mm}^{3}$ & \multicolumn{2}{|c|}{ Membrane immunoglobulin bearing } \\
\hline Neutro. & $62.5 \%$ & cells & not detected \\
\hline Mono. & $14.5 \%$ & \multicolumn{2}{|c|}{ Rosette forming cells } \\
\hline Eosino. & $18.0^{\circ} \%$ & $\mathrm{E}$ & $47 \%\left(117 / \mathrm{mm}^{3}\right)$ \\
\hline Lymph. & $5.5 \%$ & EAChu & $53 \%\left(113 / \mathrm{mm}^{3}\right)$ \\
\hline Serum protein & & \multicolumn{2}{|c|}{ Lymphocyte proliferative responses } \\
\hline Total protein & $5.8 \mathrm{~g} / \mathrm{dl}$ & \multicolumn{2}{|c|}{ (stimulation index) } \\
\hline Alb. & $71.3 \%$ & PHA & 3.3 (controls 310 ) \\
\hline$\alpha_{1}$-glob. & $5.4 \%$ & PWM & 5.0 (controls 106$)$ \\
\hline$\alpha_{2}$-glob. & $13.9 \%$ & Con $\mathrm{A}$ & 6.6 (controls 228) \\
\hline$\beta$-glob. & $8.6 \%$ & & \\
\hline \multirow[t]{2}{*}{$\gamma$-glob. } & $0.5 \%$ & \multirow{2}{*}{\multicolumn{2}{|c|}{ Skin tests for delayed-type hypersensitivity }} \\
\hline & & & \\
\hline \multicolumn{2}{|c|}{ Serum immunoglobulin } & Candida & negative \\
\hline $\operatorname{Ig} G$ & $128 \mathrm{mg} / \mathrm{dl}$ & $\mathrm{SK} / \mathrm{SD}$ & negative \\
\hline $\operatorname{IgA}$ & 0 & DNCB & negative \\
\hline $\operatorname{Ig} M$ & 0 & & \\
\hline $\operatorname{IgE}$ & $<25$ I.U. & & \\
\hline
\end{tabular}

et al., submitted for publication) (Table 1). Enzyme replacement therapy with fresh irradiated erythrocytes with normal ADA activities was tried resulting in a partial improvement of immunological impairment of the patient (Tsuchiya et al., 1979). However, he was died of Pneumocystis carinii pneumonia and bacteremia of Pseudomonas aeruginosa at the age of 19 months. No HLA-matched donor for bone marrow transplantation was found.

\section{MATERIALS AND METHODS}

Blood specimens were collected in heparinized syringes. After removal of plasma and leukocytes, the erythrocytes were washed 3 times with saline, and then lyzed by freezing and thawing in dry ice-acetone. The cell lysates were centrifuged at 3,000 rpm for $20 \mathrm{~min}$, and the supernatants were applied for enzyme assay. ADA activity in the erythrocyte lysates was measured by linked enzyme assay using $0.3 \mu$ mole adenosine (Wako, Tokyo) as substrate, endogenous nucleoside phosphorylase and exogenous $10 \mu \mathrm{l}$ of xanthine oxidase (Boehringer, Mannheim, 10 $\mathrm{mg} / \mathrm{ml}$ ) (Hopkinson et al., 1969). Increased uric acid was measured at $293 \mathrm{~nm}$ in a UVIDEC $-405 \mathrm{X}$ recording spectrophotometer (Japan Spectroscopic Co., Ltd., Tokyo).

\section{RESULTS AND DISCUSSION}

Figure 1 showed the ADA activities of erythrocytes in the patient and his rela- 


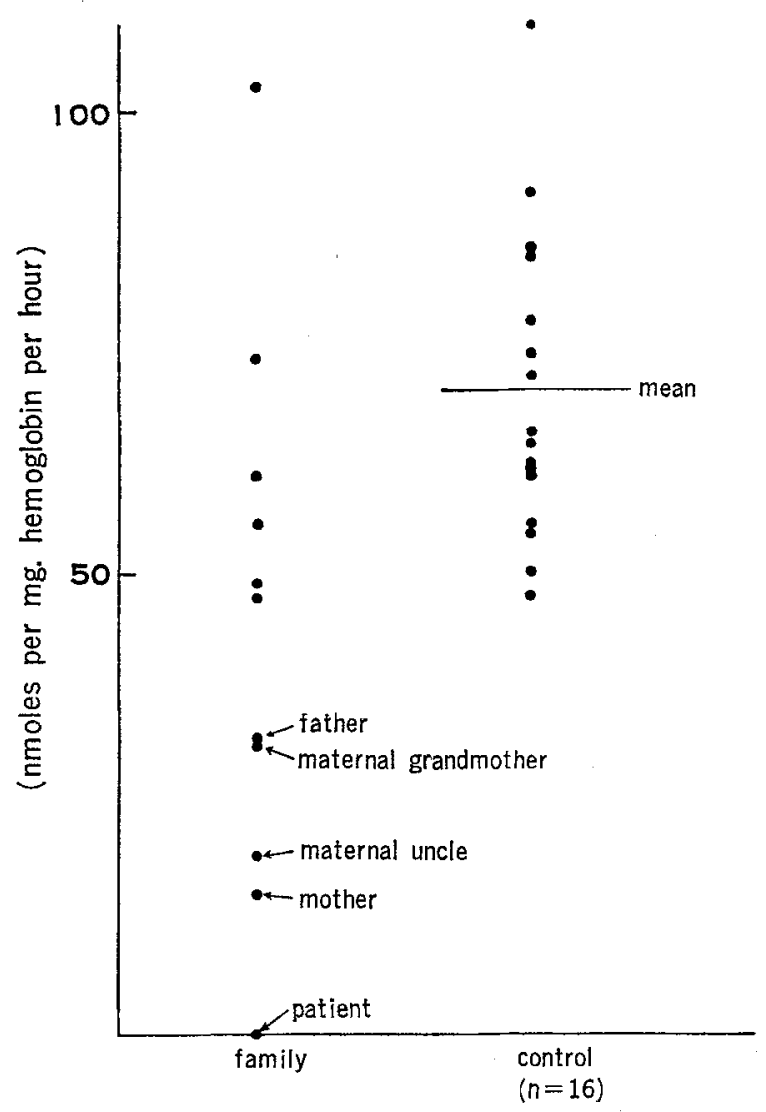

Fig. 1. ADA of erythrocytes in patient, relatives and controls.

tives, and in controls. ADA activities in 16 control subjects ranged from 47.7 to 109.7 nmoles $/ \mathrm{mg} \mathrm{Hb} / \mathrm{hr}$ with the mean value of $69.6 \pm 16.6 \mathrm{nmoles} / \mathrm{mgHb} / \mathrm{hr}$. ADA activity in the patient's erythrocytes was not detectable by the method used. Among the 10 family members extending 3 generations examined, the parents, maternal uncle and grandmother had ADA activity below the half level of the mean of controls and assumed to be heterozygotes. ADA activities in erythrocytes of other 6 relatives were within normal range. Pedigree of the family of the patient shown in Fig. 2 suggested clearly an autosomal recessive inheritance pattern of ADA deficiency disease. Nucleoside phosphorylase activities in all these specimens examined were within normal range $(2.61 \pm 0.31 \mu$ moles $/ \mathrm{mg} \mathrm{Hb} / \mathrm{hr})$.

Two sisters of the patient were died of pneumonia at a year of age, respectively. They were noticed to have lymphocytopenia and hypogammaglobulinemia. Autopsy findings of the 2nd sister revealed that the thymus and systemic lymphatic tissues were extremely hypoplastic, suggesting primary immunodeficiency. These 


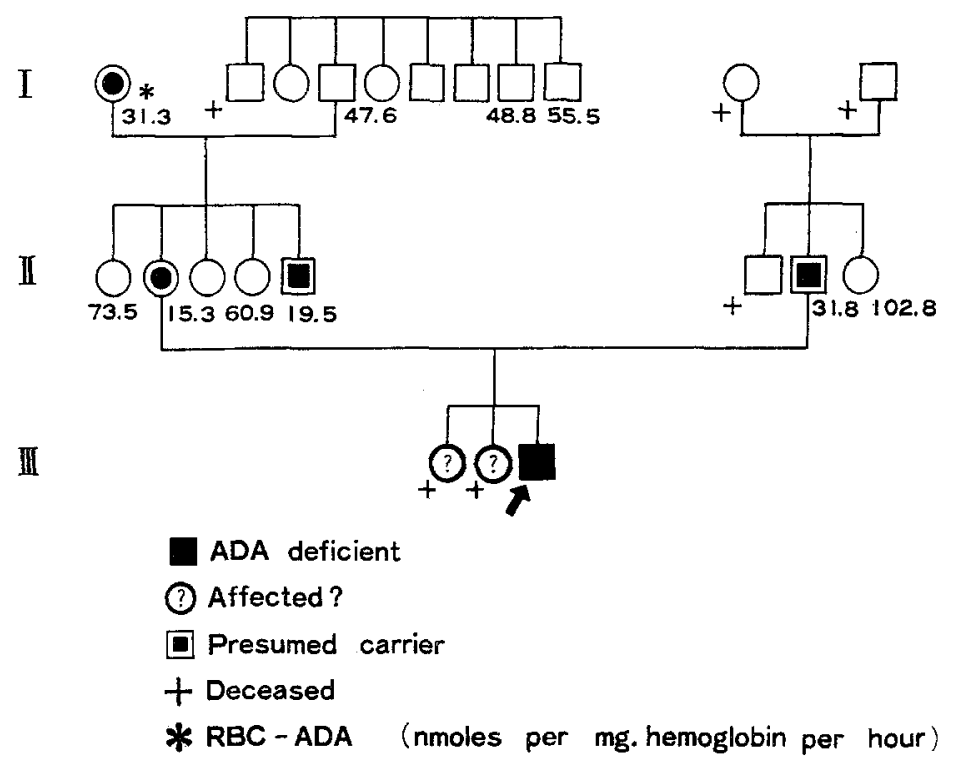

Fig. 2. Pedigree of family with ADA deficiency.

clinical and autopsy findings, in addition to the family study might suggest the sisters had ADA deficiency and SCID although ADA was not determined.

In Japan, another case of ADA deficiency disease has been found (personal communication). But the frequency in the general population of the "silent" gene (ADAo) has not been determined. Screening for ADA deficiency disease is now in progress (Ito et al., 1977), but no ADA-deficient patient has been found yet in a mass screening test in Japan.

\section{REFERENCES}

Chen, S.-H., Scott, C. R. and Giblett, E. R. 1974. Adenosine deaminase: Demonstration of a "silent" gene associated with combined immunodeficiency disease. Am. J. Human Genet. 26: 103-107.

Giblett, E. R., Scott, C. R., and Chen, S.-H. 1975. Adenosine deaminase: Genetic aspects. In: Combined Immunodeficiency Disease and Adenosine Deaminase Deficiency: A Molecular Defect. H. J. Meuwissen, R. J. Pickering, B. Pollara, and I. H. Porter, eds., Academic Press, New York, pp. 103-110.

Hopkinson, D. A., Cook, P. J. L., and Harris, H. 1969. Further data on the adenosine deaminase (ADA) polymorphism and a report of a new phenotype. Ann. Human Genet. 32: 361-367.

Ito, K., Sakura, N., Usui, T., and Uchino, H. 1977. Screening for primary immunodeficiencies associated with purine nucleoside phosphorylase deficiency or adenosine deaminase deficiency. J. Lab. Clin. Med. 90: 844-848.

Tsuchiya, S., Arai, N., Kudo, M., Konno, T., Tada, K., and Yokoyama, S. 1979. Effect of adenosine deaminase replacement therapy on a child of adenosine deaminase deficiency with severe combined immunodeficiency disease. Tohoku J. Exp. Med. 128 (3), in press. 